\title{
An Examination of the Effects on Low-Income Communities by the "Takeover" of Thrift Store Clothing by Resellers
}

\author{
Crystal $\mathrm{Ma}^{1}$ and Greg Riggio" ${ }^{1 \#}$ \\ ${ }^{1}$ California Academy of Mathematics and Science, Carson, CA, USA \\ "Advisor
}

\section{ABSTRACT}

Thrift reselling refers to when individuals purchase large quantities of clothing from thrift shops to resell at a higher price in order to make profit. As this new form of making income becomes more popular, so does a concern about how thrift reselling may affect low-income communities who rely on local thrift stores for clothing. This study proposes to find a correlation between low-income communities and thrift resellers and seeks to find how and if thrift resellers may negatively affect the accessibility of clothing for low-income individuals. By distributing a survey across Los Angeles County residents who qualify as low income, this study concludes that thrift resellers affect low-income communities negatively due to their overconsumption of clothing at thrift shops, leading to not enough clothing left over for low-income individuals. The implications of this study serve to provide research on how to improve the lives of those residing in low-income communities.

\section{Introduction}

As of 2019, the United States is home to a population of 328.2 million people, a size large enough to stand up against entire continents. With this comes a high percentage of poverty; the US Census reports 4 million people lived in poverty during 2019. Those living in poverty struggle to obtain necessities and often resort to thrift stores for affordable clothing. However, the rise of thrift resell culture threatens access to this option potentially also crossing the line for what is deemed ethical for a business.

\section{Reselling}

A resell business is one in which you buy items and sell them to make a profit. In this study, I will be referring to thrift reselling, a practice where sellers buy large amounts of inventory from low-cost, affordable thrift shops and resell them on websites or apps such as Depop or ThreadUP at a marked-up price. For example, a seller can buy a pair of jeans from Goodwill at $\$ 5.99$ and resell them for $\$ 65$, making a profit of around $\$ 59$.

Thrift reselling has become increasingly popular over the last few years, with people (particularly those who are part of Generation Z) becoming more and more open to buying clothing from resell apps or websites. According to ThreadUP, a major thrift resell website, $40 \%$ of those under the age of 24 have bought second hand in 2019 as compared to just 3 years prior in 2016 with an almost 20\% increase. From the period of 2017 to 2019, the top ten clothing and fashion apps have begun to include resell apps, with Depop and ThredUP (two popular thrift resale apps) just entering the top ten list for the first time in 2019 (Briskman, 2019). 


\section{Thrifting as a Trend}

Over the past few years, and especially over the pandemic, there has been a rise in the social media platform TikTok. Due to the popularity of this app, fashion trends have been coming and going at an alarming rate, with major fast fashion brands being unable to keep up. Influencers on the app state that they are over fast fashion, or low-cost designs that are quickly transferred from the catwalk to clothing stores, choosing instead to shop at thrift stores due to the abundance of unique, trendy pieces that cannot be found anywhere else. Influencers boast about purchasing large cartfuls of clothing to sell on resell sites, with videos gaining hundreds of thousands to millions of views. This sort of lifestyle is promoted to young viewers, who then in turn, seek to over consume thrift store clothing as well.

This trend is clear on multiple platforms, including Instagram, where the resell app Depop boasts 706,000 followers and influencers whose content focuses primarily around thrift reselling, including those such as Ruby Lyn (314k followers) and ThreadsObsessed (43.4k followers). Both influencers actively promote thrifting by filming "thrift with me" or "thrift haul" clips in which they encourage shoppers to consider thrift shops for trendy clothing.

\section{Ethics}

While selling thrifted clothing on apps such as Depop can serve as a source of income for many people, the resell business as it is now has become oversaturated, with quality pieces at thrift stores getting bought quickly and in bulk to resell for higher prices (Rex, 2020). The founder of The Ethical Fashion Roundup newsletter, Ruth MacGlip, even states that "Any '90s and '00s labels get snapped up quickly and the quality overall has definitely been slipping while prices have been driven up, meaning people who shop there due to necessity, or for a more sustainable alternative to the high street, are priced out by savvy resellers."

While these thoughts are shared by a large number of people, it is important to conduct research on the specific effects of resellers on low-income communities and determine which effects are most detrimental to those who are low-income individuals.

\section{Literature Review}

It is important to look at existing research conducted in order to understand why this study analyzes the correlation between reselling and low-income communities. This section delves into related experiments that have been conducted on a similar topic. While there are currently few studies done on the impact of reselling itself on low-income communities, some studies conducted suggest that more affluent people are beginning to shop at thrift stores typically frequented by lower income individuals, changing the overall thrift experience to "fit the demands of an affluent younger class" (Ronobir, 2020). This study by Ronobir suggests that the effects of more affluent middle to high class individuals thrifting can change thrift stores in neighborhoods with low-income residents into a more expensive practice. Ronobir's research focuses primarily on affluent individuals thrifting for personal use, but is limited as he only briefly mentions resellers, who purchase much more inventory than an average person. Instead, he focuses on the concept of thrifting becoming a staple part of affluent peoples' lives due to trends and reasons other than necessity.

While there are few studies on how affluent individuals or resellers interact with and change thrift stores, research pertaining to the relationship with thrift stores for those in low-income communities does exist. Many studies, like "The socioeconomic causes and effects of the gentrified thrifting experience", have touched on the subject and all arrived at the same conclusion, that low-income individuals rely immensely on thrift stores for accessible clothing. A study conducted on family participation patterns in local thrift economies during periods of economic stress explicitly states that "we have a lower class that sees that [thrift stores] as one of the last few places where they can afford to buy the goods that they need to maintain their standard of living" (James et al., 2010). Studies conducted by other researchers have also shown that while many people who shop at thrift stores are doing so for economic reasons, 
recently, there has been an increase in shoppers who are fashion conscious and are looking for "unique pieces" rather than price point (Zaman, 2020). Other research by Montgomery and Mitchell comes to a similar conclusion, stating that the majority of thrift shoppers are looking for affordable clothing or unusual/unique clothing pieces, but also adding that young people were more likely to be thrift store buyers while older people were more likely to be donors (Montgomery \& Mitchell, 2010). This finding is something that may directly relate to my research on the accessibility of clothing in thrift stores to low-income individuals.

However, while many studies assert the necessity of thrift stores for low-income households to access clothing, and some specifically address how middle- or upper-class individuals are negatively impacting lower income communities, there is a lack of research done on the impact of resellers, which have grown immensely in recent years. According to ThreadUP's yearly report, the number of people buying and selling thrifted clothing has been steadily increasing year by year. Limitations of past studies have left a gap in our knowledge about specific groups of affluent people, namely resellers, who are only mentioned rather than investigated. This study will make an attempt to bridge this gap by asking: How does online thrift reselling affect the accessibility of clothing in low-income communities in Los Angeles County?

My research will be a new addition to the field that addresses how thrift resellers who buy specifically from stores located in low-income communities affect the accessibility of clothing for low-income individuals. This ethnographic study will be limited to the Los Angeles area and will consist of both qualitative and quantitative data collected through a two-part survey. This survey is designed to collect the opinions of low-income individuals located in the target area (Los Angeles County). To protect user anonymity, no names of any participants will be mentioned.

This study will contribute greatly to research done for low-income communities as it will hopefully help identify an issue that affects the living conditions of lower income communities. With this knowledge, it can be possible to identify specific factors that affect how low-income individuals access clothing; this will be extremely important in causing social change, as it will inform society of the negative impacts that may be left behind on lowincome communities by more affluent people who may be unaware. On a smaller scale, this would allow for change in the structure of thrift stores in what they may promote in the future, including but not limited to more donations, an item limit, or less focus on thrift store boutiques such as Goodwill boutiques (which consist of higher end designer labels for a higher price). The results of this study can contribute to the improvement of living conditions of lowincome individuals, specifically in the accessibility of necessities such as clothing.

\section{Hypothesis}

I initially hypothesized that low-income communities would be affected negatively by the abundance of thrift resellers due to increased thrift store prices and decreased stock in stores (making it harder to find needed clothing). This hypothesis was developed based off of studies conducted analyzing how low-income individuals obtain clothing as well as their reasons for shopping at thrift stores. These studies, like those by Spencer James and Ronobir, show that low-income individuals were more likely than any other group to shop for clothing at thrift stores. One study in particular by James focuses on thrifting patterns of people of different income groups which was used to compare the habits of low-income families to middle income families. A survey was conducted to see which items were most shopped for at thrift stores and the mean from a category of 1-5 (5, meaning the most likely) was taken. In the results shown, low-income families were more likely to purchase most items from thrift stores, but especially clothing, with a mean 1.51 higher than the mean for those in middle income families, at 3.90/5 as compared to 2.39/5 (James et al., 2010). 


\section{Methods}

To test the hypothesis, both quantitative and qualitative data were collected via survey method. The survey consisted of 16 questions divided into two sections, the first being a replication of Mitchell and Montgomery's research from their papers titled "Examining the Demographic Profiles of Thrift Store Donors and Thrift Store Shoppers" and "An Examination of Thrift Store Shoppers," while the second branched off of existing research and sought to ask new questions relating to the correlation between thrift shopping as a low-income individual and reselling.

\section{Participants}

Subjects in this study were low-income individuals residing in Los Angeles County. Low-income is defined by the California Department of Housing and Community Development as below $80 \%$ of a county's median family income (calculated according to household size). This survey was distributed through forms filled out by participants on the Internet.

Participants had to indicate informed consent before receiving the survey and participating in the study. Any personal data including email addresses and first names was immediately destroyed after completion of the study. All participants volunteered to participate and were not offered any incentives. They were also able to drop out of the study at any time or skip questions they did not wish to answer.

Twenty low-income individuals located in various parts of Los Angeles County participated in this study. The survey consent form was posted on 2 different Facebook groups, 3 different Reddit forums, as well as on the social media app TikTok; the sample produced consisted primarily of students qualifying for free or reduced lunch in Los Angeles County.

\section{Part 1}

The first section of the survey replicated Montgomery and Mitchell's research (see Literature Review). Participants were asked to answer multiple choice questions asking about their reasons for thrift shopping to a range of questions like "How often do you go thrift shopping?" and "How likely are you to shop for clothing items?"

The multiple-choice questions featured a range of answers for each question type. For example, when reporting main reasons for thrift shopping, answers consisted of "Value Seeker: I saved money," "Special Purpose: I needed a unique item for a themed event," "Eccentric: I looked for unusual items. Such stores have them," "Pragmatic: I found a used product fit my needs," Collector: I looked for unique items for my collections," and "Supporter: I believed in their cause. I found things to show my support." Other questions had participants rate how much a statement represented their views on thrifting, on a scale that ranged from "Very Unlikely" to "Very Likely." The purpose of this survey was to reinforce the conclusion of similar studies done before which stated the importance of thrift shopping for low-income households to find clothing essentials.

\section{Part 2}

The second section of the survey sought to gather information about individuals' thrifting habits and opinions on resellers. This section sought to find a correlation between the two (resellers and low-income individuals). Participants were asked to answer both multiple choice and fill in the blank questions, such as: "Is most of your clothing secondhand or new?" and "Have you purchased from reselling apps/websites such as Depop, ThreadUP, or eBay recently? If yes, please state your last item purchased and the price it was purchased for (ex: Levi's jeans for \$50).” 
Most multiple-choice questions were formatted in a yes/no/unsure format so that participants do not feel inclined to answer yes or no if they are unconfident with their answer. Others let participants choose multiple answers; for example, participants could choose more than one choice from a list when asked "What types of clothing are you looking for when thrifting?"

\section{Findings}

The results of this study will be divided into three parts, each representing a corresponding part of the survey. The first part represents research replicated from Montgomery and Mitchell, and the second represents original research. The survey results are converted into percentages out of $100 \%$. Lastly, a third part is dedicated to survey results required for an understanding of the research done to answer the overall question: How does online thrift reselling affect the accessibility of clothing in low-income communities in Los Angeles County?

\section{Part 1}

Replicating Montgomery and Mitchell's study, I was correct in assuming that the main reason for the participants to thrift was to save money. The results to these questions appear in Table A. Using Montgomery and Mitchell's terms, "Value Seeking" (or to save money) was the most chosen reason with $85 \%$ of people doing so followed by "Pragmatic" (which Montgomery and Mitchell define as a "used product fitting one's needs"). 55\% of respondents chose "Pragmatic," of which all had also chosen "Value Seeking" as another reason. Then came purposes such as wanting unique or unusual items or wanting to support the thrift shop's cause. Lastly, very few people looked for collectors items and one person stated that they do not shop at thrift stores. The percentages of people who chose reasons such as wanting unique items/collectors' items/to support the store's cause were all less than $40 \%$.

As for thrifting schedules, most people (70\%) stayed within the range of thrifting anywhere from once a month to 2-3 times per year with another 30\% rarely or never thrifting. No groups thrifted weekly.

Lastly, $65 \%$ of participants answered from a scale of 1 to 5,1 being rarely/never and 5 being very likely that they were very likely to shop for clothing at thrift stores. Refer to Table B for this information. It should also be noted that when asked about their likelihood of shopping for other items in categories of "trinkets/antiques" or "houseware items/electronics/books," participants answered with the majority (55\%) choosing "rarely/never" for the former. For the latter, opinions were divided and participants chose anywhere from 1-5 evenly, meaning that it varied from person to person. When the mean was calculated from a 1-5 scale (5 meaning very likely/often, 1 meaning rarely/never), trinkets/antiques had a mean of 1.95, and houseware items/electronics/books had a mean of 2.90, while clothing had a mean of $4.05 / 5$, which was much higher than either of the others. Because of this, it is shown that clothing appears to be the most important thing looked for by low-income individuals.

Table A: Reasons for Past Purchases

\begin{tabular}{|l|c|}
\hline Reason for Purchase & Frequency of Reporting by Respondents \\
\hline Value Seeker: "I saved money" & $17(85 \%)$ \\
\hline $\begin{array}{l}\text { Special Purpose: "I needed a unique item } \\
\text { for a themed event" }\end{array}$ & $7(35 \%)$ \\
\hline $\begin{array}{l}\text { Eccentric: "I looked for unusual items. Such stores } \\
\text { have them" }\end{array}$ & $7(35 \%)$ \\
\hline
\end{tabular}




\begin{tabular}{|l|c|}
\hline Pragmatic: "I found a used product fit my needs" & $11(55 \%)$ \\
\hline Collector: "I looked for unique items for my collections" & $3(15 \%)$ \\
\hline $\begin{array}{l}\text { Supporter: "I believed in their cause. I found things to } \\
\text { show my support" }\end{array}$ & $7(35 \%)$ \\
\hline Other/Does Not Apply & $1(5 \%)$ \\
\hline
\end{tabular}

Table B: Frequently Purchased Items

\begin{tabular}{|l|l|}
\hline Item Category & $\begin{array}{l}\text { Frequency of Purchase (Calcu- } \\
\text { lated mean from 1-5 scale, from } \\
\text { unlikely to very likely) }\end{array}$ \\
\hline Trinkets/Antiques: & 1.95 \\
\hline Clothing Items: & 4.05 \\
\hline $\begin{array}{l}\text { Houseware Items/electron- } \\
\text { ics/books: }\end{array}$ & 2.90 \\
\hline
\end{tabular}

\section{Part 2}

This part of the survey asked about personal thrifting habits to get an idea of how prevalent thrifting is in low-income individuals' lives as well as whether or not the thrifting experience has changed or made finding clothing easier or harder over the last few years. Refer to Table C, D, and $\mathbf{E}$ for the results.t. When asked about the makeup of their wardrobes, $50 \%$ of participants stated that their wardrobe consisted of about $50 \%$ new and $50 \%$ secondhand/thrifted clothing. Another $15 \%$ said their wardrobe was of entirely thrifted clothing and the rest stated that they only purchased new clothing.

When asked about whether or not participants have noticed a change in thrift store pricing, $47.4 \%$ of the participants stated that they have noticed a change in thrift store pricing over the last 5 years, but still believe it to be affordable. $36.8 \%$ state that they have not noticed a change in thrift store pricing and find it affordable as it is while only $15 \%$ believe thrift store pricing to have changed in the last 5 years to become unaffordable. Overall, it seems that thrift store pricing does not have a large impact on low-income individuals.

$60 \%$ of respondents noticed resellers at the thrift store while the remaining $40 \%$ were unsure whether or not they had seen any. $47.4 \%$ of the respondents also stated that they have had a hard time finding clothing they need or desire at the thrift stores recently, which may have to do with the amount of resellers shopping at thrift shops. Overall, $35 \%$ of respondents noticed resellers and found it hard to find clothing essentials, while $15 \%$ of total respondents noticed resellers and did not find it hard to find clothing essentials. $0 \%$ of respondents either did not notice resellers and found it hard to find clothing essentials or did not notice resellers and did not find it hard to find clothing essentials. Lastly, out of the participants remaining, $10 \%$ were unsure of whether or not there were resellers but found it hard to find clothing essentials while $15 \%$ were unsure of whether or not there were resellers but did not find it hard to find clothing essentials. Lastly, when asked if they have ever purchased from a resale website or app, $84 \%$ of participants answered that they have not; one participant explicitly stated that resale websites/apps were "too expensive." 
Table C: Wardrobe Makeup

\begin{tabular}{|l|c|}
\hline Clothing Category: & Percentage of Participants \\
\hline Mostly/Entirely New: & $7(35 \%)$ \\
\hline Mostly/Entirely Secondhand: & $3(15 \%)$ \\
\hline Around Half Secondhand, Half New: & $10(50 \%)$ \\
\hline
\end{tabular}

Table D: Thrift Store Pricing

\begin{tabular}{|l|c|}
\hline Observation and Effect: & Percentage of Participants \\
\hline Thrift Store Pricing has Changed/is still affordable & $9(47.4 \%)$ \\
\hline Thrift Store Pricing has Changed/is not affordable & $3(15.8 \%)$ \\
\hline Thrift Store Pricing has Not Changed/is still affordable & $7(36.8 \%)$ \\
\hline Thrift Store Pricing has Not Changed/is not affordable & $0(0 \%)$ \\
\hline
\end{tabular}

Table E: Resellers and Clothing Availability

\begin{tabular}{|l|c|}
\hline Participant Observation: & Percentage of Participants \\
\hline Noticed resellers and found it hard to find clothing essentials & $7(35 \%)$ \\
\hline Noticed resellers and did not find it hard to find clothing essentials & $3(15 \%)$ \\
\hline Did not notice resellers and found it hard to find clothing essentials & $0(0 \%)$ \\
\hline $\begin{array}{l}\text { Did not notice resellers and did not find it hard to find clothing essen- } \\
\text { tials }\end{array}$ & $0(0 \%)$ \\
\hline $\begin{array}{l}\text { Unsure of whether or not there were resellers and found it hard to find } \\
\text { clothing essentials }\end{array}$ & $2(10 \%)$ \\
\hline $\begin{array}{l}\text { Unsure of whether or not there were resellers and did not find it hard } \\
\text { to find clothing essentials }\end{array}$ & $3(15 \%)$ \\
\hline \begin{tabular}{l} 
Not applicable/participant did not answer \\
\hline
\end{tabular}
\end{tabular}




\section{Related Findings}

In order to understand the results above, additional information was collected to gauge how low-income thrift shoppers compared to resellers. Participants were asked to state how much clothing they purchased per trip to the thrift store, in order to make a comparison to the amount purchased by resellers, which is often depicted in social media to be by the cartful. 55\% of participants stated that they purchased anywhere from 3-5 items per trip, while the remaining purchased around 1-2 items per trip. Only one person stated that they purchased 5 or more items per thrift trip.

Similarly to the research replicated in Part 1 of the survey, participants were asked what types of clothing they usually looked for when thrifting. This question was asked in order to see whether or not they were looking for trendy pieces such as resellers or if they were looking for necessities and practical wear. 57.9\% of participants stated that they were looking for practical clothing while the rest stated that they looked for unique pieces of clothing. This information shows that participants were more likely to shop for necessity than for trend.

These questions were asked in order to gain understanding of future solutions and implications of this research. For instance, by asking participants about the amount of clothing they usually purchased at the thrift store, a solution such as limiting the number of items one could buy at chain thrift stores such as Goodwill or Salvation Army may prove to be effective in making sure there was sufficient clothing for low-income individuals. It also might justify resellers' activity, as it's possible thrift store shoppers do not care about trends, but do not want to see costs rise because of trends.

\section{Limitations}

This section is separated into 2 categories, one containing limitations that are affected by outside (uncontrollable) factors, and the second containing restrictions set due to the nature of the research conducted.

\section{Outside Factors}

Due to the time constraints set for this study, I had a limited number of months to gather data and distribute the survey. Due to this, only twenty individuals participated which cannot be used to represent the 10 million people currently living in Los Angeles County. Secondly, a majority of the participants were students living in Long Beach, which only covered a small portion of the population in Los Angeles County, meaning that the research may only affect people living in the Long Beach Area. Because of the small sample size and lack of diversity in participants, this research may only be applicable to a smaller population of people. However, the Long Beach area is a good indicator of the larger LA area, as the cost of living is not radically different. According to BestPlaces, with a US average cost of living counting as an index of "100", Long Beach scores at 160.4, which is not drastically different from an index 173.3 within Los Angeles city itself. Long Beach also has a population of around 500,000 people, counting as the second largest city other than Los Angeles City.

\section{Conclusion and Implications}

My hypothesis stated that low-income communities would be affected negatively by the abundance of thrift resellers due to increased thrift store prices and decreased stock in stores. While I was correct in assuming that they would be affected negatively due to decreased stock, my research results imply there was little to no effect of a negative impact due to increased pricing, nor did survey participants notice much difference in pricing of thrift store clothing over the past 5 years. In fact, although $63.2 \%$ of respondents saw an increase in thrift store pricing, only $15.8 \%$ stated that this change in pricing affected them negatively and made thrift store clothing unaffordable. 
Therefore, it can be concluded that while resellers may be both causing a rise in thrift store prices and overpurchasing thrift store clothing, low income groups find a problem mainly with the lack of needed or desired clothing from the selection left over at stores after they've been picked over by resellers. This is an issue that has been found by my research but must be further addressed by future researchers. My research has further implications for the future of low-income communities. While it is clear that low-income communities do rely on thrift shops to purchase necessities (especially clothing), future researchers should be encouraged to conduct more thorough research in Los Angeles County on the effects of the buyer to donor ratio at thrift stores on these communities as the results of this research have shown that thrift stores do not have enough clothing to sustain both low-income households and resellers.

Some suggestions made by this research would be for chain thrift shops such as Goodwill or Salvation Army to focus their advertisements and overall attention on encouraging the donation of used clothing and such to thrift shops as there appears to be more clothing consumed than donated, as shown by a large number of participants stating that they had a hard time finding clothing at their local thrift stores. Since most respondents stated that they only purchased around 3-5 items of clothing per trip to the thrift store, further research may also address the effects of resellers by implementing a limit on items bought at thrift stores, particularly in clothing. Lastly, in the future, research may also expand through the rest of the United States rather than just Los Angeles County.

\section{Acknowledgments}

I would like to thank the California Academy of Mathematics and Science for providing resources and support throughout this project. I would also like to thank Mr. Greg Riggio for his help in revising and editing this paper as well as providing feedback throughout the research process

\section{References}

2020 Fashion Resale Market and Trend Report. (2020). ThredUP. https://www.thredup.com/resale/

Briskman, J. (2019). Poshmark Surpassed Four Million U.S Downloads in Q3 2019, Leading Clothes and Fashion App Installs. Sensor Tower Blog. https://sensortower.com/blog/poshmark-surpassed-four-million-usdownloads-q3-2019-leading-clothes-and-fashion-app-installs

James, S., Brown, R. B., Goodsell, T. L., Stovall, J., \& Flaherty, J. (2010). Adapting to Hard Times: Family Participation Patterns in Local Thrift Economies. Family Relations, 59(4), 383-395. https://doi.org/10.1111/j.1741-3729.2010.00610.x

Mitchell, M., Montgomery, R., \& Rauch, D. (2010). AN EXAMINATION OF THRIFT STORE SHOPPERS. International Journal of Nonprofit and Voluntary Sector Marketing, 14(3), 255-269. https://doi.org/10.1002/nvsm.360

Montgomery, Robert D. and Mitchell, Mark (2014) "Examining the Demographic Profiles of Thrift Store Donors and Thrift Store Shoppers," Atlantic Marketing Journal: Vol. 3 : No. 1 , Article 1. https://digitalcommons.kennesaw.edu/amj/vol3/iss1/1

Rex, H. (2020, September 4). Is Depop Gentrifying Secondhand Shopping? Refinery29. https://www.refinery29.com/en-gb/depop-secondhand-gentrification

Ronobir, J. K. (2020). The socioeconomic causes and effects of the gentrified thrifting. Finxerunt Publications. Published. https://doi.org/10.5281/zenodo.3983108

This 23-year-old gave up a corporate job to make \$5,000 a month reselling thrift store clothes through an app. (2015, May 23). Business Insider. https://www.businessinsider.com/poshmark-earning-money-20155? international $=$ true $\& \mathrm{r}=\mathrm{US} \& \mathrm{IR}=\mathrm{T}$ 
Zaman, M. M., Song, S. Y., Kwon, T. H., \& Kim, Y. K. (2017). Profiling Second-hand Clothing Shoppers with Decision Tree Predictive Model. International Textile and Apparel Association (ITAA) Annual Conference Proceedings. Published.

https://ib.dr.iastate.edu/itaa proceedings/2017/presentations/139/?utm source=lib.dr.iastate.edu\%2Fitaa p roceedings $\% 2$ F $2017 \% 2$ Fpresentations $\% 2 F 139 \& u t m$ medium=PDF\&utm campaign=PDFCoverPages

Zaman, M. M., Song, S. Y., Kwon, T. H., \& Kim, Y. K. (2020). Profiling Thrift Store Shoppers with a Decision Tree Predictive Model. Sustainability in Fashion -. Published. https://doi.org/10.31274/susfashion.11459 